\title{
Biliary Leakage after Laparoscopic Cholecystectomy versus Open Cholecystectomy
}

\author{
EMAD ELDIN F. IBRAHIM, M.D.; SHABAN M. ABDEL MAGEED, M.D.; \\ FAWZY S. FAWZY, M.D. and AMR KHEDAWY D. MOHAMMED, M.Sc.
}

The Department of General Surgery, Faculty of Medicine, Ain Shams University

\begin{abstract}
Background: Laparoscopic cholecystectomy has become the gold standard in the treatment of symptomatic gallstones. In spite of the advantages of a distinctly faster recovery and better cosmetic results, the laparoscopic approach bears a higher risk for iatrogenic bile duct injury and injury of the right hepatic artery. Bile leak after laparoscopic cholecystectomy is uncommon but can occur in $0.3-2.7 \%$ of patients. A bile leak may result in a biliary fistula, a subhepatic/subphrenic collection and localised or generalised peritonitis. Despite the widespread notion that the risk of bile leak is higher after $\mathrm{LC}$, there is a scarcity in the published literature that directly compared the risk of bile leak after LC versus open cholecystectomy.
\end{abstract}

Aim of Study: To provide cumulative data about the outcome of biliary leakage after laparoscopic versus open cholecystectomy.

Patients and Methods: In the present study, we searched Medline via PubMed, SCOPUS, Web of Science, and Cochrane Central Register of Controlled Trials (CENTRAL) from their inception till December 2018. The search retrieved 12157 unique records. We then retained 45 potentially eligible records for full-texts screening. Finally, 17 studies were included in the present systematic review and meta-analysis. Data Extraction: If the studies did not fulfill the inclusion criteria, they were excluded. Study quality assessment included whether ethical approval was gained, eligibility criteria specified, appropriate controls, and adequate information and defined assessment measures.

Results: In terms of the primary outcomes of the present study, the overall effect estimates showed that LC significantly increased the risk of bile leak compared to OC (OR 2.01, 95\% CI [1.3-3.09]; $p=0.002)$; the pooled studies showed no significant heterogeneity $(p=0.74 ; \mathrm{I} 2=0 \%)$.

Conclusion: Surgeons experienced a very low rate of postoperative bile leak following laparoscopic or open cholecystectomy; however, the risk of bile leak appears to be higher with laparoscopic compared to open cholecystectomy. The present systematic review and meta-analysis showed that the laparoscopic cholecystectomy significantly increased the risk of bile leak compared to open cholecystectomy. These data

Correspondence to: Dr. Amr Khedawy D. Mohammed, E-Mail: dramr936@gmail.com draw attention to the importance of early identification of patients, at high risk of bile leak, as it may allow specific measures or conversion to open cholecystectomy.

Key Words: Laparoscopic cholecystectomy-Open cholecystectomy - Endoscopic retrograde cholangiopancreatography.

\section{Introduction}

CHOLECYSTECTOMY is one of the most commonly performed surgical procedures worldwide, with over 750,000 operations performed annually in the United States alone [1].

First introduced in the 1980s, laparoscopic cholecystectomy has remained the gold standard for treatment of patients with GB stone disease for the past few decades. In fact, approximately $90 \%$ of cholecystectomies today are performed using a laparoscopic approach. $5 \%$ of these require conversion to an open procedure, usually because of significant inflammation, adhesions, or difficulty defining the biliary anatomy, bleeding, bile leak [2].

A biliary leak can be defined as leakage of bile from any site in the biliary tree, including the liver, hepatic ducts, cystic duct, or common bile duct. In spite of the advantages of a distinctly faster recovery and better cosmetic results, the laparoscopic approach bears a higher risk for iatrogenic bile duct injury (IBDI) and injury of the right hepatic artery. IBDI is a complication associated with significant perioperative morbidity and mortality, reduced long -term survival and quality of life, and high rates of subsequent legality [3].

Risk factors for biliary injury during cholecystectomy fall into three categories: Patient factors, operative considerations, and surgeon effects. Patient factors that increase the risk of biliary 
injury include male gender, increased age, and increased comorbidity. Operative considerations include the complexity of the operation, presence of hemorrhage, and aberrant anatomy. The most commonly indicted surgeon factors are inadequate equipment as well as limited surgical experience

IBDI can be a very serious complication that, if managed inadequately, can result in lifethreatening complications such as cholangitis, secondary biliary cirrhosis and portal hypertension. Even with successful management, quality of life may be diminished and survival may be impaired

ERCP can identify the site of the leak in $>95 \%$ of patients and can provide therapy for retained biliary stones and strictures. Endoscopy with sphincterotomy and stenting is the first line of treatment with a success rate greater than 90\% [6]

Aim of the work:

The aim of this study is to provide cumulative data about the outcome of biliary leakage after laparoscopic versus open cholecystectomy.

\section{Patients and Methods}

We performed this systematic review and metaanalysis in accordance to the recommendations of the Preferred Reporting Items for Systematic Reviews and Meta-Analyses (PRISMA) and the Metaanalyses of Observational Studies in Epidemiology (MOOSE) statements. PRISMA and MOOSE are reporting checklists for Authors, Editors, and Reviewers of Meta-analyses of interventional and observational studies. According to International committee of medical journal association (ICJME), reviewers must report their findings according to each of the items listed in those checklists $[\mathbf{7 , 8 ]}$.

\section{Study selection and eligibility criteria:}

The present review included studies that fulfilled the following criteria:

- Studies that included adults' patients who were subjected to either laparoscopic or open cholecystectomy.

- Studies that assessed the efficacy and safety of the laparoscopic cholecystectomy.

- Studies that compared the laparoscopic cholecystectomy with open cholecystectomy.

- Studies that reported any of the following outcomes: Mortality rate, morbidity rate, presence of bile duct injury, or wound infection.
- Studies that were randomized controlled trials (RCTs), prospective non-randomized studies, or retrospective studies.

We excluded non-English studies, reviews, theses, dissertations and conference abstracts, and trials with unreliable date for extraction.

\section{Search strategy and screening:}

An electronic search was conducted from the inception till December 2018 in the following bibliographic databases: Medline via PubMed, SCOPUS, Cochrane Central Register of Controlled Trials (CENTRAL), and Web of knowledge to identify relevant articles. We used different combinations of the following queries: ("laparoscopic cholecystectomy" [Mesh] OR "cholecystectomy") AND "outcomes". The search have been done with no limit regarding the year publication.

\section{Screening:}

Retrieved citations were imported into End Note X7 for duplicates removal. Subsequently, unique citations were imported into an Excel sheet and screened for eligibility; the screening was conducted in two steps: Title and abstract screening, followed by a full-texts screening of potentially eligible records.

\section{Data extraction:}

Data entry and processing were carried out using a standardized Excel sheet and reviewers extracted the data from the included studies. The extracted data included the following domains: (1) Summary characteristics of the included studies; (2) Baseline characteristics of studied populations; and (3) Study outcomes. All reviewers' independently extracted data from the included articles and any discrepancies were solved by discussion.

\section{Dealing with missing data:}

Missing standard deviation (SD) of mean change from baseline was calculated from standard error or $95 \%$ confidence interval (CI) according to Altman [9].

\section{Risk of bias assessment:}

The quality of the retrieved RCTs was assessed according to the Cochrane handbook of systematic reviews of interventions 5.1.0 (updated March 2011). Risk of bias assessment included the following domains: Sequence generation (selection bias), allocation sequence concealment (selection bias), blinding of participants and personnel (performance bias), blinding of outcome assessment (detection bias), incomplete outcome data (attrition 
bias), selective outcome reporting (reporting bias) and other potential sources of bias. The authors' judgments are categorized as 'Low risk', 'High risk' or 'Unclear risk' of bias. We used the quality assessment table provided in (part 2, Chapter 8.5) in the same book [10]

\section{Data synthesis:}

Continuous outcomes were pooled as mean difference (MD) or standardized mean difference (SMD) using inverse variance method, and dichotomous outcomes will be pooled as relative risk (RR) using Mantel-Haenszel method. The randomeffects method was used under the assumption of existing significant clinical and methodological heterogeneity. We performed all statistical analyses using Review Manager (RevMan) 5.3 or Open Meta-analyst for windows.

\section{Assessment of heterogeneity:}

We assessed heterogeneity by visual inspection of the forest plots, chi-square, and I-square tests. According to the recommendations of Cochrane Handbook of Systematic Reviews and metaanalysis, chi-square $p$-value less than 0.1 denote significant heterogeneity while I-square values show no important heterogeneity between $0 \%$ and $40 \%$, moderate heterogeneity from $30 \%$ to $60 \%$, substantial heterogeneity from $50 \%$ to $100 \%$. If any trials were judged to affect the homogeneity of the pooled estimates, we planned to perform a sensitivity analysis to assess outcomes with and without the trials that were affecting the homogeneity of the effect estimates.

\section{Assessment of publication biases:}

We intended to test for publication bias using funnel plots if any of the pooled analysis included more than 10 studies in the review [10]

\section{Results}

In the present study, we searched Medline via PubMed, SCOPUS, Web of Science, and Cochrane Central Register of Controlled Trials (CENTRAL) from their inception till December 2018. The search retrieved 12157 unique records. We then retained 45 potentially eligible records for full-texts screening. Finally, 17 studies were included in the present systematic review and meta-analysis (Fig. 1).

\section{Characteristics of the included studies:}

A total 17 studies were included in the present systematic review and meta-analysis, 12 of them included patients underwent LC only and five studies compared LC versus open cholecystectomy. Four studies were randomized controlled trials, five were prospective studies, and the rest of the studies were retrospective studies. All studies included patients with acute cholecystitis and the sample size ranged from 67 to 11,712 patients (Tables 1,2).

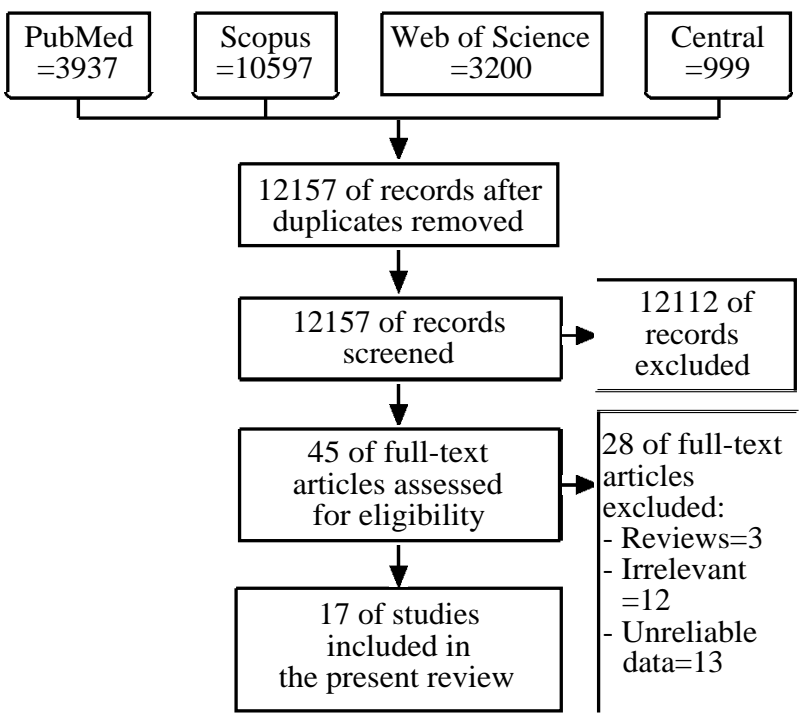

Fig. (1): PRISMA flow-chart.

Table (1): Summary Characteristics of the included studies on only patients with LC.

\begin{tabular}{lllllc}
\hline Study authors & Year & Study design & Study period & Population & Sample Size \\
\hline Viste et al. & 2015 & Prospective Study & $1992-2013$ & Patients with acute cholecystitis & 67 \\
Stanisic et al. & 2014 & Prospective Study & 2005 to 2009 & Patients with acute cholecystitis & 369 \\
Zhao et al. & 2016 & Randomized Controlled Trail & 2011 to 2012 & Patients with acute cholecystitis & 150 \\
Vuong et al. & 2015 & Retrospective Study & 2007 to 2013 & Patients with acute cholecystitis & 56194 \\
Pekolj et al. & 2013 & Retrospective Study & 1991 to 2010 & Patients with acute cholecystitis & 10123 \\
Worth et al. & 2016 & Retrospective Study & 2001 to 2011 & Patients with acute cholecystitis & 352389 \\
Ruiz-Tovar et al. & 2013 & Randomized Controlled Trail & 2010 to 2011. & Patients with acute cholecystitis & 100 \\
Nielsen et al. & 2014 & Retrospective Study & 2006 to 2010 & Elderly patients with acute cholecystitis & 4915 \\
Rothman et al. & 2015 & Prospective Study & 2006 to 2011. & Patients with acute cholecystitis & 100 \\
Van Dam et al. & 2015 & Prospective Study & 2015 & Patients with acute cholecystitis & 30 \\
Lucarelli et al. & 2015 & Randomized Controlled Trail & 2015 & Patients with acute cholecystitis & 30 \\
Parikh et al. & 2015 & Prospective Study & 2015 & Patients with acute cholecystitis & 200 \\
\hline
\end{tabular}


Table (2): Summary Characteristics of the included studies which compared LC and OC.

\begin{tabular}{|c|c|c|c|c|c|c|c|}
\hline Authors & Year & Study design & Study period & Population & Sample Size & $\mathrm{LC}$ & $\mathrm{OC}$ \\
\hline Gouma and Go & 1994 & Cross-sectional & 1991 & Patients with acute cholecystitis & 11,712 & 2932 & 8,780 \\
\hline Eldar et al., & 1997 & Retrospective study & $1992-1993$ & Patients with acute cholecystitis & 243 & 146 & 97 \\
\hline Glavic et al., & 2001 & Retrospective study & 1994-1998 & Patients with acute cholecystitis & 209 & 94 & 115 \\
\hline Chau et al., & 2002 & Retrospective study & 1994-1999 & Elderly patients with acute cholecystitis & 73 & 31 & 42 \\
\hline Catena et al., & 2012 & Open-label RCT & $2008-2010$ & Patients with acute cholecystitis & 144 & 72 & 72 \\
\hline
\end{tabular}

RCT: Randomized controlled studies. LC: Laparoscopic cholecystectomy. OC: Open cholecystectomy.

All included RCTs had low or unclear risk of bias in term of random sequence generation, allo- cation concealment, blinding, incomplete outcome data, and selective reporting (Fig. 2).

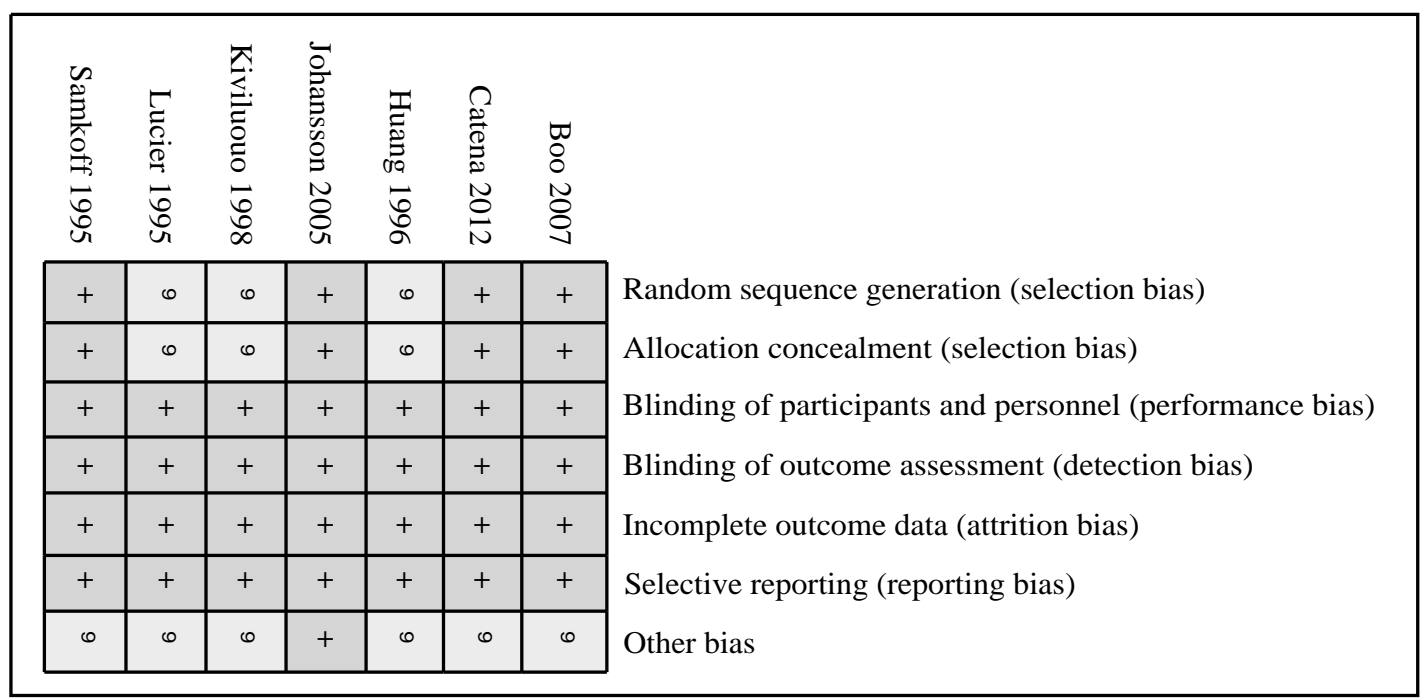

Fig. (2): Risk of bias summary.

In terms of quality of non-randomized studies, the quality score of included studies ranged from $18-21$ (accepted cut-off value is $>18$ ) (Table 3 ).

In non-comparative studies, the incidence of BDI ranged from $0.02 \%$ to $3.3 \%$. The definition of BDI varied across the studies as shown in Table (4).

The goal of surgical repair is to restore biliary tract continuity in order to prevent short-term and long-term complications. In the literature, a good long-term result is most often based on correction of the anastomotic stricture that is responsible for symptoms and long-lasting hepatic dysfunction. Two authors have established classifications for long-term results (Table 5). Both classifications are similar and are widely used for studies evaluating the results of repair of post-cholecystectomy BDI. In tertiary centers, the success rate of BDI repair from the most recent series ranges from 79 to $93 \%$ (Table 6). Two-thirds of strictures develop within 2 or 3 years following repair, and the other third arise in the ten years following repair.
Two studies report the long-term outcomes of surgical repair of BDI (Table 7). The most common complication was HJ stricture, followed by cholangitis, and cirrhosis.

\section{a- Meta-analysis results:}

\section{1-Bile leak following $L C$ :}

Twelve studies reported the incidence of bile leak, the overall effect estimates showed that incidence of bile leak was $0.1 \%(0.01 \%, 0.2 \%)$; the pooled studies showed no significant heterogeneity $(p=0.74 ; \mathrm{I} 2=0 \%)$. Fig. (3) shows the forest plot of bile leak.

\section{2- Bile leak incidence in $L C$ versus $O C$ :}

Five studies compared the incidence of bile leak between LC and OC, the overall effect estimates showed that LC significantly increased the risk of bile leak compared to OC (OR 2.01, 95\% CI [ 1.3-3.09]; $p=0.002)$; the pooled studies showed no significant heterogeneity $(p=0.74 ; \mathrm{I} 2=0 \%)$. Fig. (4) shows the forest plot of bile leak. 


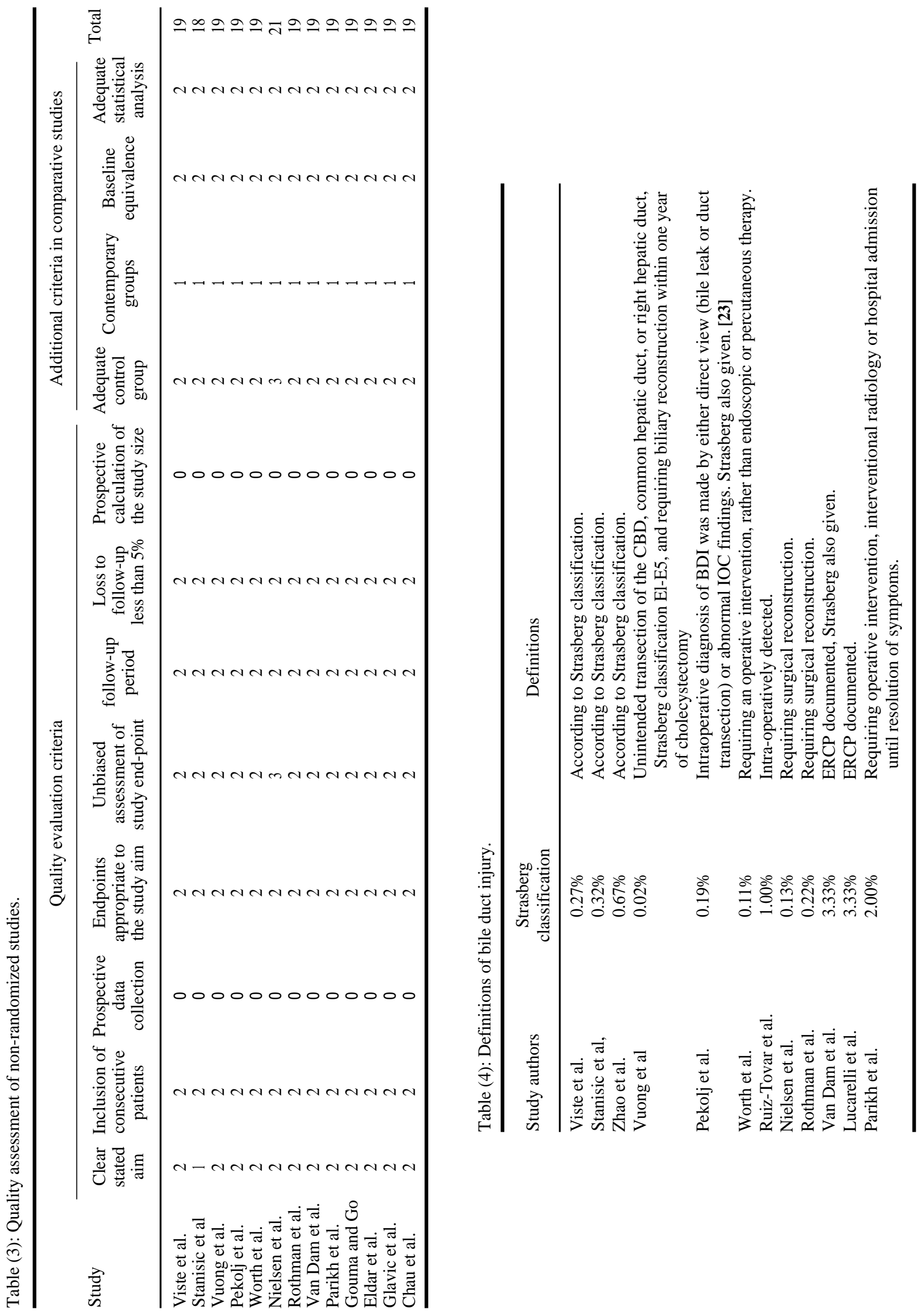


Table (5): Classifications of outcome of bile duct injury (BDI) repair.

\begin{tabular}{|c|c|c|}
\hline Grade & Result & Description \\
\hline \multicolumn{3}{|c|}{ Terblanche clinical classification: } \\
\hline I & Excellent & No biliary symptoms with normal liver function \\
\hline II & Good & Transitory symptoms, currently no symptoms and normal liver function \\
\hline III & Fair & $\begin{array}{l}\text { Clearly related symptoms requiring medical therapy and/or deteriorating } \\
\text { liver function }\end{array}$ \\
\hline IV & Poor & Recurrent stricture requiring correction, or related death \\
\hline \multicolumn{3}{|c|}{ McDonald's classification: } \\
\hline Grade A & & Normal liver function tests, asymptomatic \\
\hline Grade B & & Mild liver function test derangement, asymptomatic \\
\hline Grade C & & Abnormal liver function tests, cholangitis, pain \\
\hline Grade D & & Endoscopic or surgical revision required \\
\hline
\end{tabular}

Table (6): Results of bile duct injury (BDI) surgical repair in the main published series.

\begin{tabular}{|c|c|c|c|c|c|c|}
\hline Authors & $\begin{array}{l}\text { Number } \\
\text { of patients }\end{array}$ & $\begin{array}{c}\text { Previous } \\
\text { biliary } \\
\text { repair }\end{array}$ & Type of repair & $\begin{array}{l}\text { Duration } \\
\text { follow-up }\end{array}$ & $\begin{array}{l}\text { Long-term } \\
\text { outcome }\end{array}$ & $\begin{array}{c}\text { Development } \\
\text { of SBC }\end{array}$ \\
\hline Viste et al. & 1 & $0 \%$ & Roux-en-Y & 9.4 years & Grades A & \\
\hline Zhao et al. & 1 & $0 \%$ & Roux-en-Y & 61.9 months & Good outcome & \\
\hline Pekolj et al. & 19 & $80 \%$ & $\begin{array}{l}89.8 \% \text { Roux-en-Y } \\
(87 \% \text { Hepp-Couinaud) } \\
\text { Others: Hepaticojejunostomy, } \\
\text { repair over T-tube }\end{array}$ & 3.7 years $\pm 0,3$ & $\begin{array}{l}85 \% \text { excellent outcome } \\
6 \% \text { good results } \\
9 \%: \text { Failure with reoperation } \\
\text { for anastomotic stricture }\end{array}$ & $9.3 \%$ \\
\hline Stanisic et al. & 2 & $50 \%$ & Roux-en-Y $100 \%$ & $\begin{array}{l}28.5 \text { months } \\
{[4-5]}\end{array}$ & $\begin{array}{l}50 \% \text { excellent outcome } \\
50 \% \text { good outcome }\end{array}$ & \\
\hline Vuong et al. & 11 & $20 \%$ & Roux-en-Y 100\% & $\begin{array}{c}108 \text { months } \\
{[60-228]}\end{array}$ & $83 \%$ good or excellent results & $3.5 \%$ \\
\hline
\end{tabular}

SBC: Secondary biliary cirrhosis. HJ: Hepaticojejunostomy.

Table (7): Overview of reports on long-term outcomes after surgical repair of BDI by HJ.

\begin{tabular}{lcc}
\hline Author & Pekolj et al. & Vuong et al. \\
\hline Number of HJs & 19 & 11 \\
Overall morbidity, \% & & 8 \\
HJ stricture, \% & 11.6 & \\
Cholangitis, \% & 14.2 & \\
Intrahepatic stones, \% & 2.5 & \\
cirrhosis, \% & 6.7 & \\
Incisional hernia, \% & 3.3 & 54 months \\
Late BDI- related mortality, \% & & \\
Time to stricture formation & & \\
Follow-up time & & \\
\hline
\end{tabular}




\begin{tabular}{lll}
\hline Studies & Estimate $(95 \%$ C.I. $)$ & Ev/Trt \\
\hline Viste et al. & $0.015(0.000,0.044)$ & $1 / 67$ \\
Stanisic et al. & $0.003(0.000,0.008)$ & $1 / 369$ \\
Zhao et al. & $0.007(0.000,0.020)$ & $1 / 150$ \\
Vuong et al. & $0.000(0.000,0.000)$ & $11 / 56194$ \\
Pekolj et al. & $0.002(0.001,0.003)$ & $19 / 10123$ \\
Worth et al. & $0.001(0.001,0.001)$ & $388 / 352389$ \\
Ruiz-Tovar et al. & $0.010(0.000,0.030)$ & $1 / 100$ \\
Nielsen et al. & $0.001(0.000,0.002)$ & $6 / 4915$ \\
Rothman et al. & $0.010(0.000,0.030)$ & $1 / 100$ \\
Van Dam et al. & $0.033(0.000,0.098)$ & $1 / 30$ \\
Lucarelli et al. & $0.033(0.000,0.098)$ & $1 / 30$ \\
Parikh et al. & $0.020(0.001,0.039)$ & $4 / 200$ \\
Overall (1^2=92\%, $p<0.001)$ & $0.001(0.000,0.002)$ & $435 / 424667$ \\
\hline
\end{tabular}

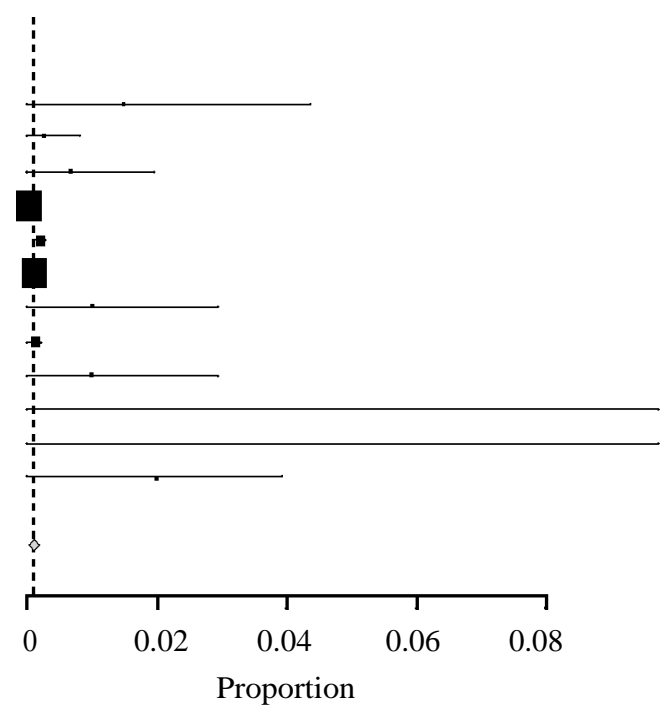

Fig. (3): Forest Plot of bile leak.

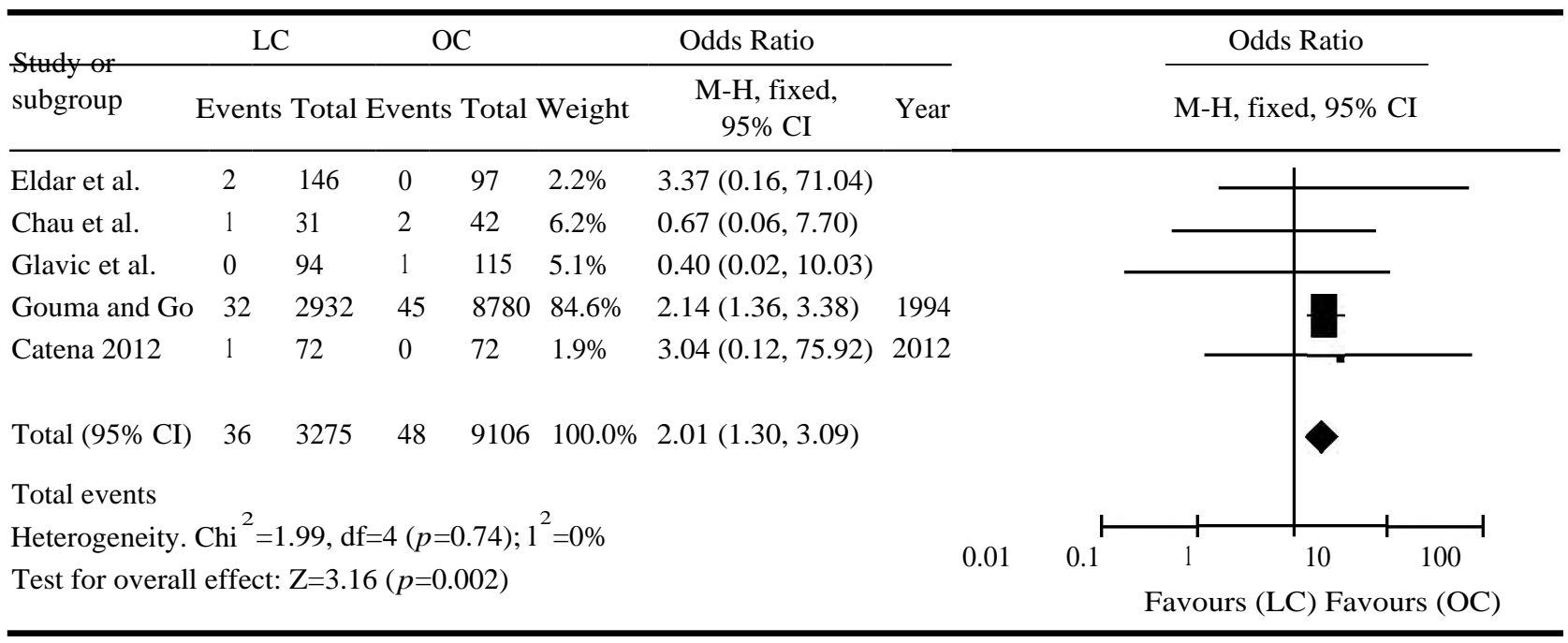

Fig. (4): Forest Plot of bile leak incidence in LC versus OC.

\section{Discussion}

The incidence of gallstones is $10-15 \%$ and the lifetime recurrence rate of symptoms or complications in such patients is about 35\%. Laparoscopic cholecystectomy has become the gold standard in the treatment of symptomatic gallstones. The major advantages of laparoscopic cholecystectomy (LC) include less postoperative pain, less time required for hospitalization and recovery, and better cosmetic results [11].

In spite of the advantages of a distinctly faster recovery and better cosmetic results, the laparoscopic approach bears a higher risk for iatrogenic bile duct injury and injury of the right hepatic artery. Bile leak after laparoscopic cholecystectomy is uncommon but can occur in $0.3-2.7 \%$ of patients.
It is defined as the persistent leakage of bile from the biliary tree. This can arise from an injury to the common bile/hepatic duct but it is generally accepted that the vast majority arise from the cystic duct stump or a sub-vesical duct of Luschka [4]

A bile leak may result in a biliary fistula, a subhepatic/subphrenic collection and localised or generalised peritonitis. Clearly, this can be associated with significant morbidity and even mortality, particularly if it is not identified and treated at an early stage [3].

Despite the widespread notion that the risk of bile leak is higher after LC, there is a scarcity in the published literature that directly compared the risk of bile leak after LC versus open cholecystectomy. Thus, we conducted the present systematic 
review and meta-analysis in order to provide cumulative data about the outcome of biliary leakage after laparoscopic versus open cholecystectomy.

In the present study, we searched Medline via PubMed, SCOPUS, Web of Science, and Cochrane Central Register of Controlled Trials (CENTRAL) from their inception till December 2018. The search retrieved 12157 unique records. We then retained 45 potentially eligible records for full-texts screening. Finally, 17 studies were included in the present systematic review and meta-analysis.

Up to the age of 50 years, acute calculous cholecystitis is three times more common in women than in men and about 1.5 times more common in women than in men thereafter [12]. In the present systematic review and meta-analysis, most of the included studies showed a trend towards female predominance among patients with acute cholecystitis.

Previous reports have shown that the rate of clinically relevant bile leaks after conventional open cholecystectomy ranges between 0.1 and $0.5 \%$. In contrast, biliary leakages have increased in the era of LC by up to 3\% [13]. In the present systematic review and meta-analysis. The incidence of bile leak was $1.1 \%$ in the LC group and $0.53 \%$ in the conventional open cholecystectomy group.

In line with our findings, Gouma and Go [14] performed a cross-sectional study in all surgical departments in The Netherlands to analyze the number of repair procedures for bile duct injury, the techniques and complications of this treatment. A total of 11,712 cholecystectomies were performed, of which 2,932 were laparoscopic and 8,780 were conventional. Thirty-two bile duct injuries resulted from laparoscopic cholecystectomy $(1.1 \%)$ and 45 resulted from conventional cholecystectomy $(0.5 \%)$.

Similarly, Peters and colleagues [15] assessed the safety, efficacy, and morbidity of LC. During the first 6 months of 1990, the authors performed 100 consecutive laparoscopic cholecystectomies. There was one minor bile duct injury requiring laparotomy and t-tube insertion, two postoperative bile collections. The incidence of bile leak was $2 \%$.

Additionally, Barkun and colleagues [16] assessed risk factors for postcholecystectomy biliary leaks and their clinical course and management. in the laparoscopic era were gathered prospectively and retrospectively from an ongoing surgical database and following a review of hospital charts.
Sixty-four patients were included over a 5-year study period. The incidence of leaks was $1.1 \%$ among patients entered in a laparoscopic cholecystectomy database.

Albasini and colleagues [17] reported their experience of bile leakage following LC regard to both its incidence and management. From a consecutive series of $500 \mathrm{LC}$, in which both operative cholangiography and drainage of the gallbladder bed were routine, bile leakage was identified in ten patients $(2 \%)$.

In terms of the primary outcomes of the present study, the overall effect estimates showed that LC significantly increased the risk of bile leak compared to OC (OR 2.01, 95\% CI [1.3-3.09]; $p=0.002)$; the pooled studies showed no significant heterogeneity $(p=0.74 ; \mathrm{I} 2=0 \%)$.

In concordance with our findings, Al Mallohi and colleagues [18] performed a meta-analysis to evaluate the effect of Laparoscopic versus open cholecystectomy. The authors conducted this metaanalysis using a comprehensive search of Cochrane database of systematic reviews, PubMed, Medline, EMBASE, and Cochrane central register of controlled trials till 15 March 2018. Eleven studies have been included with a total of 80691 patients: 41485 in the laparoscopic and 39206 into the open cholecystectomy groups. The rate of bile leakage rate was not influenced by the technique.

Similarly, Shawhan and colleagues [19] sought to determine the incidence of bile leak at a teaching hospital and identify risk factors for predicting BLs. A retrospective review was performed analyzing all cholecystectomy with between September 2004 and September 2011. A total of 1,799 cholecystectomies performed during the study period. Univariate analysis demonstrated that surgery type (laparoscopic versus open) increased the patient's risk of bile leak.

In contrary, Keus and colleagues [20] conducted a systematic review and meta-analysis studies to compare the beneficial and harmful effects of laparoscopic versus open cholecystectomy for patients with symptomatic cholecystolithiasis. Thirty-eight trials randomised 2338 patients. Most of the trials had high bias risk. The bile duct injury proportions were $0.2 \%$ in both groups. No significant differences were present and there were no discrepancies between the four quality components in the subgroups. As no heterogeneity was present (risk difference $0.00,95 \%$ CI -0.01 to 0.01 ). 
Similarly, Coccolini and colleagues [21] performed a systematic-review with meta-analysis and meta-regression of trials comparing open vs. laparoscopic cholecystectomy. Electronic searches were performed using Medline, Embase, PubMed, Cochrane Central Register of Controlled Trials (CCTR), Cochrane Database of Systematic Reviews (CDSR) and CINAHL. Ten trials have been included with a total of 1248 patients: 677 in the LC and 697 into the OC groups. There were no significant differences in the bile leakage rate.

The exact causes of such heterogeneity between our findings and the abovementioned studies are unclear; however, it can be attributed to various methodological factors. For the example, the above two systematic reviews included only randomized controlled trials; while our study included a wide range of study designs. Moreover, the sample size of the included studies was notably higher in our meta-analysis than the abovementioned two systematic reviews. The quality of the included studies may be another factors explaining this heterogeneity.

\section{Conclusion:}

Surgeons experienced a very low rate of postoperative bile leak following laparoscopic or open cholecystectomy; however, the risk of bile leak appears to be higher with laparoscopic compared to open cholecystectomy. The present systematic review and meta-analysis showed that the laparoscopic cholecystectomy significantly increased the risk of bile leak compared to open cholecystectomy. These data draw attention to the importance of early identification of patients, at high risk of bile leak, as it may allow specific measures or conversion to open cholecystectomy.

\section{References}

1- CAMPANILE F.C., CARRARA A., MOTTER M., ANSALONI L. and AGRESTA F.: Laparoscopy and Acute Cholecystitis: The Evidence. Laparosc. Cholecystectomy, p. 59-72, 2014.

2- AGRESTA F., CAMPANILE F.C., VETTORETTO N., SILECCHIA G., BERGAMINI C., MAIDA P., et al.: Laparoscopic cholecystectomy: Consensus conferencebased guidelines. Langenbeck's Arch. Surg., 400: 42953, 2015.

3- FONG Z.V., PITT H.A., STRASBERG S.M., LOEHRER A.P., SICKLICK J.K., TALAMINI M.A., et al.: Diminished Survival in Patients with Bile Leak and Ductal Injury: Management Strategy and Outcomes. J. Am. Coll. Surg., 226: 568-76.e1, 2018.

4- BADER H.: Iatrogenic biliary injuries in patients who underwent laparoscopic cholecystectomy. Sci. J. Al-Azhar Med. Fac. Girls, 2: 11, 2018.
5- RUSTAGI T. and ASLANIAN H.R.: Endoscopic management of biliary leaks after laparoscopic cholecystectomy. J. Clin. Gastroenterol., 48: 674-8, 2014.

6- LLACH J., BORDAS J.M., ELIZALDE J.I., ENRICO C., GINÈS A., PELLISÉ M., et al.: Sphincterotomy in the treatment of biliary leakage. Hepatogastroenterology, 49: 1496-8, 2002.

7- MOHER D., LIBERATI A.T.J. and A.D.: The PRISMA Group. Preferred Reporting Items for Systematic Reviews and Meta-Analyses: The PRISMA Statement. Ann. Intern. Med., 151: 264-9, 2009.

8- STROUP D., BERLIN J. and MORTON S.: MOOSE Checklist for Meta-analyses of Observational Studies. JAMA, 28315: 14-5, 2000.

9- ALTMAN D.G. and BLAND J.M.: Standard deviations and standard errors. BMJ, 331: 903, 2005.

10- GREEN S., HIGGINS P., ALDERSON P., CLARKE M., MULROW D.C. and OXMAN D.A.: Cochrane Handbook: Cochrane Reviews: Ch 8: Assessing risk of bias in included studies. Cochrane Handb. Syst. Rev. Interv., Vol. 6, p. 310, 2011.

11- ACAR T., KAMER E., ACAR N., ATAHAN K., BAG H., HAC1YANL1 M., et al.: Laparoscopic cholecystectomy in the treatment of acute cholecystitis: Comparison of results between early and late cholecystectomy. Pan. Afr. Med. J., 26: 49, 2017.

12- PHATAK U.R., ALBARADO R. and EACHEMPATI S.R.: Management of cholecystitis in high-risk patients. Acute Cholecystitis, p. 137-46, 2015.

13- RENZ B.W., BÖSCH F. and ANGELE M.K.: Bile Duct Injury after Cholecystectomy: Surgical Therapy. Visc. Med., 33: 184-90, 2017.

14- GOUMA D.J. and GO PMNYH.: Bile duct injury during laparoscopic and conventional cholecystectomy. J. Am. Coll. Surg., 178: 229-33, 1994.

15- PETERS J.H., ELLISON E.C., INNES J.T., LISS J.L., NICHOLS K.E., LOMANO J.M., et al.: Safety and efficacy of laparoscopic cholecystectomy: A Prospective analysis of 100 initial patients. Ann. Surg., 213: 3-12, 1991.

16- BARKUN A.N., REZIEG M., MEHTA S.N., PAVONE E., LANDRY S., BARKUN J.S., et al.: Postcholecystectomy biliary leaks in the laparoscopic era: Risk factors, presentation, and management. Gastrointest Endosc., 45: 277-82, 1997.

17- ALBASINI J.L.A., ALEDO V.S., DEXTER S.P.L., MARTON J., MARTIN I.G. and McMAHON M.J.: Bile leakage following laparoscopic cholecystectomy. Surg. Endosc., 9: 1274-8, 1995.

18- AL MALLOHI N.A., ALMOFARREH M.K., ABDALRUHMAN ALFARRAH B., ALBALBISI M.B., ALAMOUDI A.M., SHARAHILI M.N., et al.: Laparoscopic versus open cholecystectomy. Int. J. Community Med. Public Heal, 5: 2217, 2018.

19- SHAWHAN R.R., PORTA C.R., BINGHAM J.R., McVAY D.P., NELSON D.W., CAUSEY M.W., et al.: Biliary Leak Rates After Cholecystectomy and Intraoperative Cholangiogram in Surgical Residency. Mil. Med., 180: 565-9, 2015. 
20- KEUS F., J D.J., HG G. and CJHM L.: Laparoscopic versus open cholecystectomy for patients with symptomatic cholecystolithiasis. Chochrane Collab, 1-3, 2009.
FAGIUOLI S., Di SAVERIO S., et al.: Open versus laparoscopic cholecystectomy in acute cholecystitis. Systematic review and meta-analysis. Int. J. Surg., 18: 196-204, 2015.

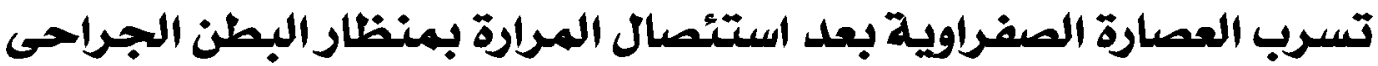

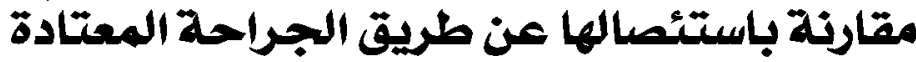

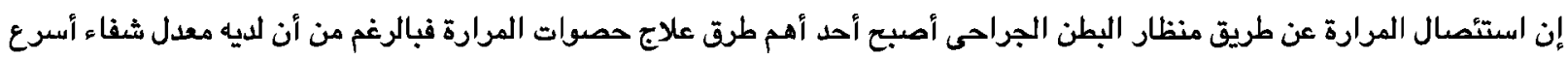

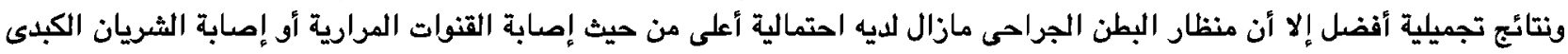

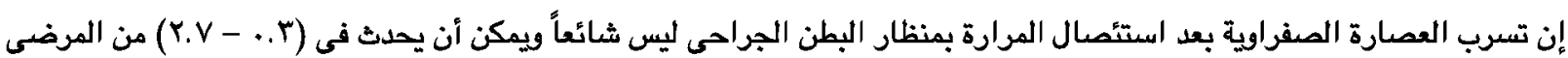

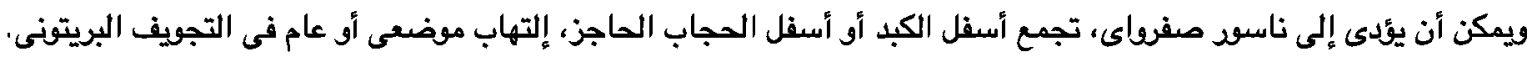

وبالرغم من الاعتقاد السائد بأن معدل حدوث تسرب العصارة الصفراوية أعلى إذا تم استئصال المرارة بالمنظار الجراحى إلا أنه مازال

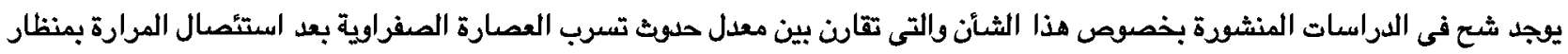
البطن الجراحى أو بالجراحة المعتادة.

لذلك قمنا بعمل مراجعة منهجية وتحليل بيانات الدراسات السابقة من أجل الحصول على معلومات إضافية فيما يتعلق بحلوث تسرب العصارة

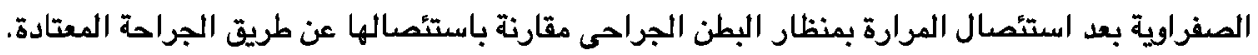

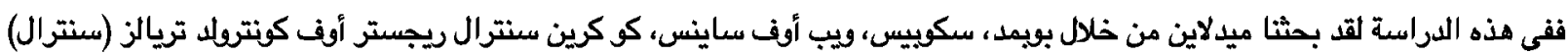

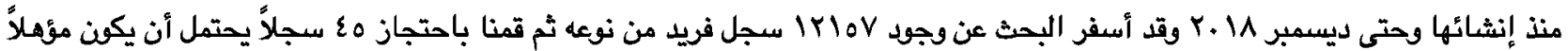
من أجل فحص النص كاملاً.

أخيراً دراسة كانت مشمولة فى هذه المراجعة المنهجية وتحليل بيانات الدراسات السابقة. ففى هذه المراجعة كانت غالبية الدراسات المشمولة تشير إلى هيمنة الإناث خلال مرضى الإلتهاب الحصوى المرارى الحاد.

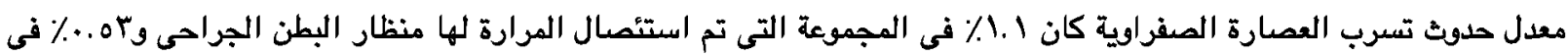

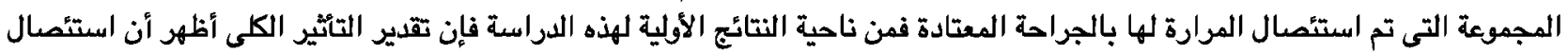
المرارة بمنظار البطن الجراحى قد زاد من معدل حلوث تسرب العصارة الصفراوية مقارنة بالجراحة المعتادة. 